\title{
The Perceptions of Educators on Skilful Conversation As A Strategic Tool to Improve Teaching and Learning in Secondary Schools
}

\author{
Kholeka Constance Moloi \\ Vaal University of Technology, Faculty of Human Sciences \\ Vanderbijpark South Africa \\ Email:conniem@vut.ac.za \\ Bennie Grobler \\ Vaal University of Technology, Faculty of Human Sciences \\ Vanderbij/park, South Africa \\ Email:bennieg@uj.ac.za
}

\section{Doi:10.5901/mjss.2014.v5n15p256}

\begin{abstract}
This article reflects on the quantitative study that was conducted with educators to examine their perceptions on skilful conversation as a strategic tool to improve teaching and learning in secondary schools. Drawing on the body of relevant literature and quantitative data the researchers discuss the potential and limits of skifful conversation and how it could be used as a strategic tool to improve teaching and learning in secondary schools. The researchers found the subjective theories and the theory of Senge et al. (2006) on team learning to be relevant as theoretical perspectives. A structured questionnaire was administered to educators in the selected secondary schools. Hypotheses are presented as data analysis and discussion of the results. Each hypothesis becomes a discursive conversation between data, analyses and theory and it is hoped that the findings arising from this study may offer meaning to and understanding of the importance of skilful conversation as a strategic tool for effective teaching and learning in secondary schools, despite bureaucratic control.
\end{abstract}

Keywords: Organisational communication, leaders as communicators, effective teaching and learning, information sharing, strategic tool

\section{Introduction}

Since the advent of democracy many government policies relating to human rights, as defined in the Bill of Rights, have been used to govern how organisations such as schools within South Africa manage relations between employers and employees. Within the Bill of Rights, everyone has the right to freedom of expression, which includes freedom of the press and media as well as freedom to receive or impart information or ideas (Bill of Rights, 1996:1). The issue of the right to express oneself implies the ability to communicate. Schools, like all other organisations, use various channels to communicate with the stakeholders that they serve (Puth, 1994:3). These channels of communication include written and oral presentations, as well as interpersonal and small-group, visual, ethical and technological means (Walker, 2006: ix). Our interest in this study is to examine how secondary schools could use skilful conversation in order to improve teaching and learning. According to Ross (2014:1), skilful conversation or communication is that which allows people to interact freely, exchange ideas and listen and respond appropriately, thereby generating good thinking. Ideally, this dialogue would include insightful questioning and also regular summaries to ensure that everyone agrees that a shared understanding has been reached. Dixon (2014:1) suggests that the skilful conversation process serves two purposes, one of which is to gain consensus and a deep understanding of some fundamentals of the school business, and the other, to illustrate what typically goes wrong when not achieving the goals set.

Skilful conversation is a set of activities involved in managing and orchestrating all internal and external communications aimed at creating a favourable point of view among the stakeholders on which the organisation depends (Ross, 2014:1). Organisational communication involves the sharing of information within any organisation, particularly by the management team. Puth (1994:44-45) suggests seven contexts within which management communicates: (i) management communication barriers, (ii) management communication style, (iii) communication and motivation, (iv) communication and conflict management, (v) communication in problem solving and decision making, (vi) communication and change, and (vii) communication and leadership. These communication contexts have, according to Puth, become 
particularly important as a result of the shift of emphasis from task-oriented to people-oriented management and the tendency to move beyond management to organisational leadership (p.44). To facilitate skifful conversation, school principals will usually need to have or develop considerable interpersonal skills, which include the ability to speak and write effectively as well as to listen attentively, in order to assist in information sharing within their schools and beyond (Business Dictionary.com 2014:1). Where successfully managed, conversation should benefit from every member's knowledge, experience and creativity. In the knowledge age, argues Ross (2014:1), business success increasingly hinges on engaging colleagues, customers and associates in conversations that question reality, encourage learning, tackle tough challenges, tap aspirations and enrich relationships. The challenge then, is for managers to learn how to manage dialogue successfully for effective understanding and dynamic results (Puth, 1994:44). This means that management teams should come to a deep understanding of the key issues in the organisation, which include such fundamental questions as:

- What is our recipe for making teaching and learning effective?

- Who are our targeted customers?

- How should we go about maintaining good learner outcomes or academic achievement?

Consequently, skilful conversation should be a truly stimulating and fruitful conversation that generates thought and/or inspired action. For Senge et al. (2006), skilful discussion is a conversation that lies near the midpoint of a continuum between advocacy and inquiry:

Raw debate $>$ Polite discussion > Skifful discussion > Dialogue

These scholars contend that in skiful discussion the group intends to come to some sort of closure, to make a decision, reach agreement or identify priorities. In dialogue, the intention is exploration, discovery and insight (Senge et al. 1996). Skilful discussion has some of the techniques of dialogue, but the outcomes are decisions, priorities, and action plans. However, the members of the group learn to make their thought processes visible, to bring assumptions to the surface and challenge them and to look more closely at sources of disagreement. Over time, the quality of thinking and interacting improves. Corporate communication is therefore an important vehicle through which the school community (the SMTs, educators, students and parents) can, in the light of human rights, express themselves by producing ideas that are useful to talk about and to listen to, as well as show care and share the best teaching and learning practices for effective teaching and learning. For Puth (1994: v), skilful conversation means the sharing of meaning.The need for effective conversation or communication creates a context within which shared ideas and purposes in the school community can be developed and nurtured and an effective strategy implemented to improve teaching and learning practices in the school. In this regard, skilful conversation becomes a starting point for strategy formulation.

\section{Problem Statement}

Given that the provision of public schooling in South Africa is the responsibility of the elected government of the day, it cannot be divorced from its social, political, cultural, ideological and economic contexts. It has become apparent that lack of skilful conversation in a school can lead to teachers and the School Management Teams (SMTs) not focusing on the same school goals. The researchers have observed that in the selected secondary schools of the Zeerust Central Region, the educators have no motivation to improve their teaching and learning practices because it seems that they are not actively involved in the decision making that affects their work (Moloi, 2005:72). The researchers also observed that educators tend to be unclear with regard to numerous issues such as the creation of a desired work culture and its implications for service delivery at all levels. The major variables of the problem are manifested in the continued struggle about issues of democratic practices within the school, for example, as articulated by Ramphele in the Sunday Times of September 2012, in which she states: 'Africa continues to wrestle with the challenges of transition from post-colonial underdevelopment to claim the $21^{\text {st }}$ century. For Africa to successfully claim its rightful place in a globally interconnected and interdependent world, it will have to make a fundamental shift from liberation struggle politics to democratic politics'. She further states that Africa suffers from weak political, social and economic institutional systems and frameworks for planning and implementing appropriate policies. Problems such as union strikes tend to affect teaching and learning processes within schools, particularly those that are located in predominantly underprivileged contexts. Thus, societies' problems are in many ways inseparable from the schooling processes.

In view of the above, the research questions are:

- What is the value of skilful conversation?

- What is the relationship between skilful conversation and effective teaching and learning?

- How can skilful conversation be used as a strategy to improve teaching and student learning? 


\section{Aims of the Study}

The aim of this research is to investigate ways in which skilful conversation could be used to improve teaching and learning in secondary schools of the Zeerust Central Region.

In view of the main aim above the specific aims are to:

- Explore the value of skilful conversation.

- Describe the relationship between skilful conversation and effective teaching and learning.

- Suggest ways in which skilful conversation could be used as a strategy to improve teaching and student learning.

\section{Literature Review}

The researchers draw from relevant literature to examine skilful conversation as a strategic tool to improve teaching and learning. Although the researchers chose the quantitative mode of research, they found subjective theories to be relevant to this study because they examined the perceptions of teachers on skilful conversation as a strategic tool to improve teaching and learning. The subjective theories of Bell and Bush (2006) focus on individuals within organisations. Subjective theories hold that each person is assumed to have a unique and subjective perception of the organisation, with events having different meanings for each participant. Consequently, organisations are portrayed as the manifestations of the values and beliefs of individuals, rather than the concrete realities of bureaucracy (p. 24). In schools, individual teachers, support staff and learners have different values and aspirations according to their own background and motivation. The school, therefore, is not the same reality for all its participants. Given these multiple realities, skilful conversation becomes a strategic imperative in order to communicate individual and organisational expectations and needs as well as the subjective experiences of participants within the school.

The researchers also borrow from the theory of Senge et al. (2006) on the learning organisation, which advocates that when people are engaged in skilful conversations they are able to build schools in which teachers can share their abilities and be creative and learners can achieve academically. For Senge, when skilful conversation is coupled with team learning and systems thinking there is a possibility of developing schools with a culture of reflection and the skill of collaborative inquiry. In this regard, Blandford (1997:86) argues that effective schools learn and develop through a process of continuous reflection and feedback. When reflection is a permanent feature of every activity in a school, teaching and learning can become more effective. Reflective conversation should include issues such as what needs to be improved, who will be responsible and the criteria to be used (Kaufman, 1995:73). In view of the foregoing, successful schools would start with the ongoing quest to find answers to several key questions:

- Why are we in the business we are in? What is our purpose?

- Where are we today?

- Where do we want to be in the future?

- How do we operate today?

- How will we operate in the future?

Skilful conversation is, therefore, a central and most important strategic tool in a school and the ultimate source of competitive advantage (Senge et al. 1996:353). Successful schools are those that provide the conversation structure within which teachers are able to talk downwardly, upwardly, horizontally and diagonally (Gibson, Ivancevich \& Donnelly, 1994:580). Skilful conversation is regarded by Van der Heijden (1996:274) as a 'learning loop' of perception, conceptualisation and action in the school, which begins with an in-depth analysis of the issues under discussion. This loop is viewed as an informal but structured discussion on issues, resulting in a clear understanding and forwarding of the ideas generated to all members of the school. Van Staden et al. (2007:10) suggest that communicating effectively with colleagues, clients and employees results in better employee and customer relations, saves time and money, enhances decision making, ensures successful problem solving and facilitates increased productivity.

Successful schools value teacher participation in creating a context for open discussion which focuses on enhancing their competence in making schools work. The researchers contend that the extent to which teacher participation is facilitated in the discussion of school matters is determined by the enthusiasm and the support of the SMT in communicating critical success factors that underpin present and future performance within the school. This can happen only by utilising a platform that provides a strategic focus for skilful discussion and fluid conversations. 


\section{Research Design and Methodology}

The design of this research project is quantitative, between groups and between subjects, manipulating quasiindependent variables by using different participants (Field 2009) who were assigned particular conditions or positions for which they inherently qualified, such as, for example, gender. The respondents indicated their responses on a structured questionnaire, allowing the researchers to determine whether various independent groups of respondents differed statistically significantly from one another with respect to the dependent variables, which in this research were the factors obtained from the analysis of the items in Section B of the questionnaire. The selected units of analysis were educators in the secondary schools of the Zeerust Central Region.

\subsection{Research Instrument}

The structured questionnaire that was used to collect the data consisted of two sections. Section A contained 16 questions, asking respondents to provide certain biographical and demographic details, which served as the independent variables in the research. Section B contained 40 questions, requesting respondents to indicate the extent of their agreement or disagreement with items posed regarding skilful conversation as a strategic tool for improving teaching and learning. The researchers used the latest version of Norusis (2010), which is the PASW Statistics 18.0 guide to data analysis. The data were first subjected to a frequency analysis, which is shown in detail in the section on the descriptive statistics. The data in section B were subjected to the process of factor analysis, again using PASW 18.0 (Norusis, 2010). The resulting factors were analysed for normality (Norusis, 2010) and possible differences between factor mean scores were investigated using t-tests or Analysis of Variance tests (Norusis, 2010). Where necessary, non-parametric tests were also used (Norusis, 2010). The various tests used in the analysis are discussed in detail in the study.

\subsection{Description of the sample used}

A population is the set of rudiments upon which the research is focused and to which the results obtained by testing the sample should be generalised (Bless \& Higson-Smith, 2004: 85). Again, population is defined as the total set from which the individuals or units of study are chosen. In this instance, the population for this study comprised 39 secondary schools in the Zeerust Central Region. Of these schools, 32 are headed by male principals and 7 by female principals. Six of the schools are located in the urban area and 33 are in the rural area. A sample representative of 20 secondary schools was selected from the defined population of 39 secondary schools in the Zeerust Central Region by selecting schools 1, 3, 7, 9 and so on up to 39. This sample was selected randomly, to enable each member of the population to have an equal chance of being selected. One school did not return the questionnaires. Each of the 20 schools received 12 questionnaires with a covering letter requesting completion by at least four educators in promotion posts such as principals, deputy principals and heads of department, and by eight educators on post level one. One hundred and eighty questionnaires were returned, of which 172 were suitable for further analysis. This researcher then analysed the data from this sample using SPSS 20.0.

\subsection{Data analysis}

The structured questionnaire consisted of 40 closed-ended items. The questions were designed to obtain the perceptions of educators and principals on skilful conversation as a strategic tool in secondary schools. Questions were formulated around the aspects of classroom practices, learner assessment practices, departmental policies, parental involvement and external and internal environments. The 40 items were designed to collect the perceptions of educators at various post levels regarding the importance and the frequency of use of skilful conversation as a strategic tool for successful secondary schools.

The construct validity of the measuring instrument was investigated by means of factor analysis. According to Borg, Gall and Gall (1993:269), factor analysis is a correlation technique that examines a large number of items and determines whether they cluster into a smaller number of underlying factors. The principal objective of factor analysis is to construct a smaller number of variables that do a good job of conveying the information present in a larger number of variables. The Kaiser-Meyer-Olkin (KMO) value on the 20 items in Section B of the questionnaire was 0.901 and the Bartlett's sphericity value was $p<0.0005$. These values were both within the normal parameters for reducing items to a more parsimonious number of factors while explaining as much of the common variance as possible (Field, 2009:636 645). Principal Components Analysis (PCA) with varimax rotation resulted in two factors regarding the importance of 
skilful conversations, namely the importance of skilful conversations between educators ( $\alpha=0.922)$ and the importance of skilful conversations between educators and principals $(a=0.89)$. The same procedure was followed with respect to the frequency of skilful conversations aimed at making schools successful. The KMO value of 0.895 and Bartlett's sphericity value of $p<0.0005$ again indicated that fewer factors were feasible. A PCA procedure followed by varimax rotation resulted in two factors, which explained $75.6 \%$ of the variance present. The first factor (FC1.1) was named the frequency of skilful conversations between educators $(\alpha=0.89)$ and the second was named frequency of skilful conversations between educators and principals $(\alpha=0.90)$. The items in the first factor are provided in Table 1.1 together with mean score and rank order.

Table 1.1: Table showing items in FC1.1 with mean score and rank order

\begin{tabular}{|c|l|c|c|c|}
\hline Item & Description: Frequency of skilful conversations between educators & Mean Score & Rank Order & Factor (FC1.1) \\
\hline C11 & Methods of learners' discipline & 3.81 & 1 & C1.1 \\
\hline C13 & Implementation of Integrated Quality Management System & 3.81 & 1 & C1.1 \\
\hline C7 & Any difficulties they may experience in learner assessment practices & 3.71 & 3 & C1.1 \\
\hline C15 & Newly developed policies of the Department of Education & 3.71 & 3 & C1.1 \\
\hline C9 & Methods of giving feedback to the learners & 3.70 & 5 & C1.1 \\
\hline C17 & Methods of involving parents in the school's activities & 3.58 & 6 & C1.1 \\
\hline C19 & Resource allocation & 3.56 & 7 & C1.1 \\
\hline C3 & Different methods of teaching & 3.51 & 8 & C1.1 \\
\hline C1 & Difficulties they may experience in preparing lessons & 3.41 & 9 & C1.1 \\
\hline C5 & Interaction with other schools & 3.01 & 10 & C1.1 \\
\hline \multicolumn{1}{|c|}{ Average } & 3.58 & & \\
\hline
\end{tabular}

The mean score of 3.58 indicates that respondents had the perception that they sometimes too often involved themselves in skilful conversations with other educators. The data in Table 4.1 also indicate that the respondents had the perception that skifful conversations around methods of disciplining learners (C11) and on how to implement the Integrated Quality Management System (IQMS) (C13) were perceived as important and hence often discussed. As the IQMS system would include aspects of discipline pertaining to learners, this indicates that learner discipline is perceived as a key ingredient for a successful school. Learner discipline is viewed as growth from dependence to independence, in the course of which learners are expected to develop a strong sense of character and values that enable them to meet challenges with confidence and competence. Skilful conversation should help to create a school where each teacher and student will set personal and academic goals and reach beyond them.

The item regarding how often interaction with other schools was discussed had the lowest mean score of 3.01, indicating that educators and principals seldom discuss interaction with other schools. This can have a detrimental effect on a school, as 'no man is an island'. Thus, educators need to come together and discuss curriculum matters with their colleagues. Educators can reach greater understanding when they are discussing and practising the teaching and learning activities together.

Networks should also be established through professional teacher support forums where educators collaborate with the subject advisors and their colleagues in discussing the curriculum. A series of workshops needs to be planned in order for educators and principals to be updated on current trends in the teaching and learning process. It is in these workshops that educators and principals will mentor and support each other.

The items in the second factor, the frequency of skilful conversations between educators and principals (FC1.2), are given in Table 1.2.

Table 1.2: Table showing items in FC1.2 with mean score and rank order

\begin{tabular}{|c|c|c|c|c|}
\hline Item & Description: Frequency of skilful conversations between educators and principals & Mean Score & Rank Order & Factor \\
\hline $\mathrm{C} 12$ & Methods of learners' discipline & 3.71 & 1 & C1.2 \\
\hline C16 & Newly developed policies of the Department of Education & 3.59 & 2 & $\mathrm{C} 1.2$ \\
\hline C14 & Implementation of Integrated Quality Management System & 3.56 & 3 & $\mathrm{C} 1.2$ \\
\hline C18 & Methods of involving parents in the school's activities & 3.54 & 4 & $\mathrm{C} 1.2$ \\
\hline $\mathrm{C} 20$ & Resource allocation & 3.43 & 5 & $\mathrm{C} 1.2$ \\
\hline $\mathrm{C} 8$ & Any difficulties they may experience in learner assessment practices & 3.29 & 6 & $\mathrm{C} 1.2$ \\
\hline
\end{tabular}




\begin{tabular}{|l|l|c|c|c|}
\hline C10 & Methods of giving feedback to the learners & 3.13 & 7 & C1.2 \\
\hline C6 & Interaction with other schools & 2.89 & 8 & C1.2 \\
\hline C2 & Difficulties they may experience in preparing lessons & 2.82 & 9 & C1.2 \\
\hline C4 & Different methods of teaching Average & 2.79 & 10 & C1.2 \\
\hline \multicolumn{2}{|c|}{ A.28 } & & \\
\hline
\end{tabular}

The mean score of 3.28 indicates that skilful conversations between educators and principals are perceived as something that seldom occurs. This perception is probably due to the fact that public schooling in South Africa is largely bureaucratic and hierarchical and conversations between the various promotional levels do not easily occur as principals are the persons who are held accountable for everything that happens in the school. When compared with the mean of FC1.1, it appears that it is probably easier to have fruitful discussions with someone at the same level as you, in other words, a discussion between peers. The difference between the two means of -0.30 is statistically significant at the $1 \%$ level, indicating that the argument above regarding hierarchical levels is probably sound.

Items C11 (methods of learner discipline) and C16 (newly developed policies of the Department of Education) are both perceived as something which is often discussed with the principal. This is probably because both are issues that are central in school planning and as such require a great deal of thinking and discussion. Principals and educators should be able to talk about their understanding of the benefits of the newly developed policies or about frustrations with their implementation, and this communication should not degenerate into a top-down presentation of Departmental policy. An open dialogue is essential, especially around aspects such as teacher evaluation systems, as they are concerned with the future advancement or not of educators in the system. It is worthwhile considering what Senge (1996:274) has to say about the use of power and the game playing that accompanies it. According to him, one needs a genuine sense of common vision and values, for without them there is nothing to motivate people beyond self-interest. An organisational climate dominated by merit rather than politics is the 'way to go.' In such a climate one does 'what is right and this predominates over who wants what done.' However, Senge warns that such a climate also demands openness, where the norm is one of speaking openly and of being able to challenge your own thinking via reflection.

In an effort to find a relationship between the two dependent variables, namely frequency of skilful conversations between educators (FC1.1) and frequency of skilful conversations between educators and principals (FC1.2), their factor means will be tested against the various independent variables present in the research. For example, say we wished to test whether the skilful conversations change depending on the post level occupied. If we tested the factor mean of educators at level 1 in the education system against persons occupying higher promotional posts we would expect persons at higher levels to have more positive perceptions about skilful discussions. At the multivariate level, two independent groups can be compared for possible statistical differences in their mean scores, using an appropriate multivariate test such as Wilk's Lambda $(\Lambda)$. This means that the vector means of the two independent groups are compared in respect of the two factors considered together. Should a statistically significant difference be found at this multivariate level then Student's t-test is used in respect of each of the variables taken separately. The appropriate hypotheses could be:

Ho $\Lambda$ - There is no statistically significant difference between the vector means of the two post-level groups regarding the two factors taken together.

$\mathrm{Ha} \wedge$ - There is a statistically significant difference between the vector means of the two post-level groups regarding the two factors taken together.

At the univariate level, the hypotheses would be:

Hot - There is no statistically significant difference between the mean scores of the two post-level groups in respect of each factor taken separately, namely:

Hot1 - Skilful conversations between educators

Hot2 - Skilful conversation with the principal

Hat - There is a statistically significant difference between the mean scores of the two post-level groups in respect of each factor taken separately, namely:

Hat1 - Skilful conversations between educators

Hat2 - Skilful conversation with the principal

Both of the dependent variables (factors) contained 10 items. Their scales thus need to be considered as one scale in terms of the following representation

Minimum1 2345 Maximum

(x 10) 1020304050

A score between 40 and 50 would thus indicate that respondents have the perception that that skilful conversation 
is something that often occurs in their schools. A score of 30 would indicate that respondents have the perception that that skilful conversations sometimes occur in their schools and would be of moderate importance. A factor means of between 10 and 20 would indicate that the respondents feel that skilful conversation is something which very seldom occurs in their schools.

The appropriate data to test the hypotheses are provided in Table 1.3.

Table 1.3: Significance of differences between the two post-level groups regarding the following two factors

\begin{tabular}{|c|c|c|c|c|}
\hline Factor & Group & Factor Mean & $\begin{array}{l}\text { Wilk's Lambda } \\
\text { (p-value) }\end{array}$ & $\begin{array}{l}\text { Student's t-test } \\
\text { (p-value) }\end{array}$ \\
\hline Skilful conversations between educators & Educators & 35.67 & \multirow{4}{*}{$0.000^{* *}$} & \multirow{2}{*}{$0.031 *$} \\
\hline$(\mathrm{FC} 1.1)$ & Promotion posts & 36.21 & & \\
\hline Skilful conversations between educators & Educators & 32.71 & & \multirow{2}{*}{$0.010^{* *}$} \\
\hline and principals (FC1.2) & Promotion posts & 32.91 & & \\
\hline
\end{tabular}

${ }^{* *}=$ Statistically significant at the $1 \%$ level $(p<0.005)$

* = Statistically significant at the $5 \%$ level $(p>0.01$ but $p<0.05)$.

The data in Table 1.3 indicate that the null hypotheses cannot be accepted. Educators' in promotion posts (HODS, Principals. Deputy Principals) have statistically significantly higher factor means with respect to skilful conversations both between educators and between educators and principals.

In respect of three or more independent groups, multivariate differences are investigated by means of Multivariate Analysis of Variance (MANOVA) in respect of the three factors considered together. The vector mean scale scores are compared and should any difference be revealed at this multivariate level then Analysis of Variance (ANOVA) is used to investigate which of the two factors is responsible for the significant statistical difference. Pairwise comparisons of groups are made either by means of Scheffé or the Dunnett T3 tests.

The differences among the age groups will now be discussed. The hypotheses are similar to the ones set before, and owing to limitations of length, they will not be stated again. However, the appropriate values are provided in Table 1.3 .

Table 1.4: Significance of differences between the three age groups in respect of the two factors

\begin{tabular}{|c|c|c|c|c|}
\hline Factor & Group & Factor mean & $\begin{array}{c}\text { Manova } \\
\text { (p-value) }\end{array}$ & $\begin{array}{c}\text { Anova } \\
\text { (p-value) }\end{array}$ \\
\hline \multirow{3}{*}{ Skilful conversations between educators (FC1.1) } & $<35 \mathrm{yrs}$ & 35.47 & \multirow{6}{*}{0.085} & \multirow{3}{*}{0.135} \\
\hline & $35-39 \mathrm{yrs}$ & 36.33 & & \\
\hline & $40+y r s$ & 35.62 & & \\
\hline \multirow{3}{*}{ Skilful conversations between educators and principals (FC1.2) } & $<35 \mathrm{yrs}$ & 31.74 & & \multirow{3}{*}{0.065} \\
\hline & $35-39 \mathrm{yrs}$ & 33.06 & & \\
\hline & $40+y r s$ & 35.53 & & \\
\hline
\end{tabular}

** Statistically significant at the $1 \%$ level $(p<0.01)$

* Statistically significant at the $5 \%$ level $(p>0.01$ but $p<0.05)$

The data in Table 1.4 indicate that the three age groups do not differ statistically significantly from one another at the multivariate level and hence the null hypothesis cannot be rejected. This is also so at the univariate level. Thus one could say that the various age groups have the perception that skilful conversations sometimes occur between themselves (FC1.1), whilst such conversations seldom occur between educators and principals (FC1.2). However, this finding could be due to chance factors and hence the differences are not significant as they could be the result of sampling error.

There were numerous other independent groups that were tested for possible statistical associations but none were found in respect of gender, mother tongue, teaching experience and type of school. Any significant differences found are indicated by examination of the factor means in Table 1.5. 
Table 1.5: Mean scores of the independent groups in respect of the two factors involved in skilful conversations

\begin{tabular}{|l|l|c|c|}
\hline \multirow{2}{*}{ Independent Group } & \multicolumn{2}{|c|}{ Category Name } & \multicolumn{2}{c|}{ Factor Mean Scores } \\
\cline { 3 - 4 } & & \multicolumn{1}{c|}{ FC1.1 } & FC1.2 \\
\hline \multirow{2}{*}{ Educator organisation } & SADTU & $36.00^{*}$ & 32.87 \\
\cline { 2 - 4 } & Other & $34.57^{*}$ & 32.31 \\
\hline \multirow{2}{*}{ Attendance of educators } & Excellent & $36.74^{*}$ & $34.14^{\star}$ \\
\cline { 2 - 4 } & Average/Poor & $35.20^{*}$ & $31.91^{*}$ \\
\hline \multirow{2}{*}{ Attendance of learners } & Excellent & $37.60^{\star}$ & 33.06 \\
\cline { 2 - 4 } & Average/Poor & $35.39^{*}$ & 32.68 \\
\hline \multirow{2}{*}{ Level of discipline } & Excellent/Good & $36.59^{*}$ & $33.82^{\star}$ \\
\cline { 2 - 4 } & Average/Poor & $35.00^{*}$ & $31.73^{\star}$ \\
\hline
\end{tabular}

FC1.1 Skilful conversations between educators

FC1.2 - Skilful conversations between educators and principals

* = Statistically significant differences present between independent groups.

With respect to educator organisations, educators who belong to the South African Democratic Teachers Union (Sadtu) have a statistically significant higher factor mean score than educators in other organisations. This may be due to the fact that Sadtu members frequently attend workshops where they are informed about the implementation of educational legislation and for this reason they probably do discuss these matters with one another more frequently. With respect to skilful conversations between educators and principals there are no significant differences but both groups have the perception that such conversations seldom occur. This is a matter of concern as it possibly indicates that roles are defined in terms of expectations in educational actions and that these roles are the institutional blueprints for action. As such, an undue emphasis is placed on the nomothetic dimension and hence the typical bureaucracy results, characterised by hierarchy of authority, rules and regulations and specialisation. An undue emphasis on bureaucratic role expectations is unlikely to foster skilful conversations between educators and principals.

The next three independent groups in Table 1.5 are all involved in the organisational climate that prevails in the school. Excellent levels of attendance by educators are seen to promote a climate where educators are often involved in skilful conversations with one another. This makes sense as open dialogue regarding the importance of excellent attendance is likely to lead to action in support of such levels of attendance. Excellent levels of educator attendance are in direct proportion to skilful conversations between principals and educators, as poor attendance is highly unlikely to facilitate fruitful conversations between all educators involved in teaching and learning in the school. Hence the better the levels of teacher attendance are perceived to be the more likely is it that fruitful conversations will occur. The perceived levels of discipline in the school are also likely to be related to educator and learner attendance as attendance levels are often used as indicators of discipline in the school.

\section{Summary of Empirical Findings}

The results indicated that successful schools in the Zeerust Central Region are grounded in two fundamental factors, namely:

- discussion with everybody

- discussion with the principal.

Multiple regression analysis revealed that the subjects underlying discussion with one another in schools in order of fundamental importance are: methods of learners' discipline, implementation of IQMS, any difficulties being experienced in learner assessment practices, newly developed policies, methods of giving feedback to the learners, methods of involving parents in the school's activities, resource allocation, different methods of teaching, difficulties being experienced in preparing lessons, and interaction with other schools. These areas comprise the discussion amongst educators on the creation of successful secondary schools in the Zeerust Central Region.

Multiple regression analysis also revealed that the subjects underlying discussion with the principal in order of importance are: methods of learners' discipline, newly developed policies, implementation of IQMS, methods of involving parents in the school's activities, resource allocation, any difficulties being experienced in learner assessment practices, methods of giving feedback to the learners, interaction with other schools, difficulties being experienced in preparing lessons, and different methods of teaching. The study found that the elements of successful schools lie in the way that the SMTs involve educators and other stakeholders in talking about the improvement and effectiveness of teaching and 
learning within the school. It is the principal's responsibility to show genuine care for the educators and demonstrate great interest in their well-being. This kind of attitude will allow educators to know how meaningful their input is and that they impact on the ultimate success of the school. The educators may then have the incentive to continuously reflect on, talk about and improve both their performance and that of the learners.

The empirical findings also indicated that skilful conversations are more likely to occur between educators than they are between educators and principals. The perceived level of discipline in the school seemed to be a useful indicator for educator attendance levels. Thorough deliberation of the importance of educators acting as role models for good attendance is likely to influence learner attendance in a positive way as well as improving perceptions of discipline in a school. When discussing the implementation of Departmental policy it is important that all the different hierarchical levels participate in an open dialogue with one another where the norm is one of trust among all stakeholders. In such a climate one can speak openly and be able to reflect on your own thinking. A school climate where doing what is right rather than doing who wants what done is linked to fruitful conversations between all stakeholders and it is here where teamwork can act as a useful link between different levels in the bureaucratic structure.

\section{The Findings of the Literature Review}

The findings of the relevant literature survey indicated the importance of talk between the educators and the principal, which results in everyone reflecting on and inquiring about his or her role in the school. The literature revealed that organisations aim to communicate the same message to all their stakeholders and to transmit coherence, credibility and ethic. Skilful conversations help an organisation to explain its mission and to combine its many visions and values into a cohesive message to stakeholders. Thus, the concept of skilful conversation could be seen as an integrative communication structure linking stakeholders to the school.

The findings of the relevant literature reveal that skilful conversation motivates educators and principals to talk about the achievement of success in their schools. The success is based on effective teaching and learning together with high expectations for all the learners. Skilful conversation provides a conversational framework within which educators are able to talk about the relevant aspects of the curriculum and methods of achieving their desired goals. This skilful conversation unites educators in spontaneously and voluntarily working together without the principal's supervision (Stoll \& Fink, 1996:88). Educators are able to share ideas and materials in more accurate forms, including mutual observation and focused reflective enquiry. The literature also reveals that skilful conversation in a school focuses continuously on teaching and learning. The ongoing skilful conversation enables educators to review their teaching strategies and learner performance. This kind of dedication brings improvement and better performance for both the educators and learners. When educators are engaged in skilful discussion their level of expertise benefits the learners and generates the best results for the school. Skilful conversation therefore motivates educators to teach and learners to learn.

The literature has revealed that educators in successful schools know more about the learners they teach, that is, the ways in which they learn according to their different backgrounds. When preparing daily lessons educators need to focus on the type of learner they want to prepare. This enables the school to adapt to the way that learners learn and will also help to prepare learners for competition in the global world. Educators' collaboration in bringing coherence to the curriculum is an important factor in learners' success. Educators must become assessment literate for the enhancement of good quality learning, as assessment is the necessary gathering of data about learners' performance (Stoll \& Fink, 1996:124).

\section{Skilful Conversation as a Strategic Tool to Improve Teaching and Learning in Secondary Schools}

For Walker (2006:13), effective communication with employees can increase morale, productivity, performance and workforce retention. Van Staden et al. (2007: xiv) point out that language and communication pave the information highway that makes globalisation possible. For individuals, they may either represent enormous stumbling blocks in professional and personal relationships or may act as a means of expressing ability and creativity. Skilful conversation is a deliberate ongoing process on which day-to-day school practices hinge in order to communicate change, align teaching and learning processes, set standards for performance and continually monitor and measure results. It provokes ideas and innovation, inspiring action and learning from what happens and sharing that experience (Manning, 2002:36). Expanding these views, we argue that corporate conversation is a key strategic tool that has always been the starting point for new ideas, new ways of being and new ways of doing, by means of which people who would otherwise feel alone with their ideas and concerns can interconnect with others. 
Kaplan and Norton (2001:1) assert that in today's business environment, strategy implementation has become more important than the quality of strategy itself. However, Kaplan and Norton argue that many organisations have difficulty implementing well-formulated strategies (i.e. the unique and sustainable ways by which organisations create value) because strategies are changing but the tools for measuring them have not kept pace (p. 2). Indeed, no organisation can function properly without a good system of communication (Van Staden et al. 2007:10). For Dixon (2014:2), a 'fierce conversation' has four objectives that help to build trust and relationships in the evolving business world. In a 'fierce conversation', any leader, manager or employee seeks to:

- Interrogate reality - Reality is a moving target. Each person's own view of reality - each person's individual perspective - isn't necessarily shared by others, even if they're a part of the same conversation.

- Provoke learning - Using skilful conversation to uncover and share the realities of everyone involved leads to greater understanding and opens the possibilities of more optimal decisions.

- Tackle tough challenges - Having the knowledge of each person's unique perspective will enable the tough challenges to be tackled to move toward resolution.

- Enrich relationships - Often forgotten or overlooked, this objective is where respect and engagement truly occur as a result of more authentic and transparent conversations.

The basic premise - and this is a key to employee engagement - is that what we talk about, how we talk about it and who is invited into the conversation determines what will or will not happen inside our organisations. Senge et al. (2006) point out that teams unquestionably benefit from dialogue - from exploring shared meaning - but they also have the everyday need to come to a pressing conclusion, decision or plan. To accomplish this work productively, skilful discussion incorporates some of the techniques and devices of dialogue and action learning, but is always focused on tasks.

\section{Recommendations}

The researchers recommend that schools should adopt the practice of ongoing talking amongst the educators concerning what is important and valuable in their working environment. Educators should notice, through skifful conversation, the importance of having a joint focus and common goals in their schools. It is through the establishment of such joint goals that educators will start talking about team teaching and mentoring for others. This will lead to educators becoming committed to and confident about their work because open discussion about work alleviates fear. Principals of schools should take responsibility for encouraging educators to speak their minds and voice their concerns openly without any fear of intimidation or negative criticism. Since people have different perceptions, principals should also accommodate this when discussing school matters with the educators. It is also recommended that principals should discuss with the educators their emotional and physical well-being, achievements, weaknesses and talents - all these embedded in trust, respect, care and support for educators. School principals are encouraged to involve educators in talking about school success and to enable them to look beyond their job description for ways to improve. The conversation should be based on how best teaching and learning can be enhanced. It is recommended that educators be allowed opportunities to collaborate on and discuss the curriculum and their teaching methods. The principal should strive to arouse a desire in educators to talk and act voluntarily without his or her supervision. To create successful schools, the school management team should engage educators in discussing departmental policies, teaching and learning and resources.

This study also recommends that educators need to have a better knowledge of the learners they teach. This will determine their teaching styles as they will be aware of these learners' multiple intelligences. Educators should present learners with the information essential to their learning in a clear and concise manner, which will increase the likelihood that they will perform tasks correctly. It is crucial for educators to explain to learners why the knowledge or skill is important. Relating the usefulness of the new learning to life outside the school would also be helpful, as learners would be motivated to learn the skills and knowledge. This will be relevant to the learners because they will know that they can rely on the learned skills and knowledge for universal competence and their success in future. Learners will be helped to succeed when educators collaborate in terms of sharing ideas with other expert educators.

\section{Conclusion}

The problem of this research has been stated and the key components which have been included are the nature of skilful conversation and effective teaching and learning in secondary schools. Data from this study have provided evidence that skilful conversation as a strategic tool has an effect in making secondary schools successful. In light of this, the 
researchers believe that the idea of skifful conversation is a good one; however, we know that schools in South Africa are too bureaucratic and hierarchical for fruitful conversations to occur. Yes, it is what theory and virtually all leadership literature recommends - but the reality in education is not so. We think that principals do not necessarily have to be leaders - but that they need only to manage (plan, organise, control and evaluate, with an emphasis on control) and our data seem to support our contention. Fruitful conversations, unfortunately still belong to the ideal world as in reality they seldom occur. In fact these researchers are left wondering whether a school principal can function effectively by just concentrating on management tasks such as planning, organising, controlling and evaluating. We think this unlikely to be so as school principals need to influence others to do the tasks at hand and for this they need to be capable of using fruitful conversations as a strategy for reaching learners via the influence of teachers and meaningful others.

\section{References}

Apple, M.W. (2004). Ideology and curriculum. Third Edition. New York: Routledge Falmer.

Bell, L. \& Bush, T. 2006. The policy context. In T. Bush \& L. Bell (eds.). The principles and practice of educational management, London: Paul Chapman, pp. 3-33.

Bill of Rights. No. 108 of 1996. Chapter 2 of the Constitution of the Republic of South Africa. Legistated 15 January 1996. The Government of South Africa.

Blandford, S. 1997. Middle Management in Schools. How to Harmonise. Managing and Teaching for an effective School. London: Pitman Publishing.

Bless, C. \& Higson-Smith, C.H. 2004. Fundamentals of social research methods. An African perspective. Third edition. Kenywn: Juta.

Borg, W.R; Gall, J.P. \& Gall, M.D. 1993.Applying educational research. A practical guide. New York: Longman.

Business Dictionary. com. 2014. Corporate communication. Available:

Dixon, N. 2014. What makes organizational conversation effective? Participant skill or skillful design. [Online] Available:http://www.google.co.za/url?q=http://www.nanacydixonblog.com/2014/02/Accessed 4/2/2014.

Gibson, J.L, Ivancevich, J.M. \& Donnelly, Jr, J.H. 1994. Organisations: Behaviour, structure, processes. USA: Irwin, Inc.

Holtz, S. 2007. Corporate conversations. A guide to crafting effective and appropriate internal communications. New Delhi: Prentice-Hall of India.

Kaplan, R.S. \& Norton, D.P. 2004. Strategy maps. Converting intangible assets into tangible outcomes. Boston, Massachusetts: Harvard Business School Publishing Company.

Kaufman, C. 1995. 'Strategic Conversation'. Journal of Management Consulting, May, Vol. 9 No.3, $72-73$.

Manning, T. 2002. Making sense of strategy. United States of America: Zebra.

Maree K \& Pietersen, J. 2009. Sampling. In: Maree, K. (ed.) First steps in research, pp.171-181. Pretoria: Van Schaik.

Moloi, K.C.2005. The school as a learning organization. Reconceptualising school practices in South Africa. $2^{\text {nd }}$ ed. Pretoria: Van Schaik. Norusis, M.J. 2010. PASW statistis 18 guide to data analysis. Chicago: Prentice Hall.

Puth, G. 1994. The communicating manager. Pretoria: J.L. van Schaik Publishers.

Ramphele, M. 2012. Drop struggle politics. Sunday Times. Review. September 23, 2012.

Ross R. 2014. Skillful discussion. Protocols for reaching a decision-mindfully. [Online] Available: Edison.schoolwires .net/cms/lib2/.../58/.../Skillful_Discussion.pdf. Accessed: 4/2/2014.

Senge, Kleiner, A., Roberts, C., Ross, R.B. \& Smith, B.J. 1996. The fifth discipline fieldbook: strategies and tools for building a learning organisation. London: Nicholas Brealey.

Senge, M.P. 2006. The Fifth Discipline. The art \& practice of the learning organisation. London: random House.

Stoll, L. \& Fink, D. 1996. Changing our schools. Philadelphia: Pon University.

Van der Heijden, K. 1996. Scenarios: The Art of Strategic Conversation. England: John Wiley \& Sons.

Van Staden, E; Marx, S. \& Erasmus-Kritzinger, L. 2007. Corporate communication. Getting the message across in business. Second edition. Prtoria: van Schaik.

Walker, R. 2006. Strategic business communication. An integrated, ethical approach. Australia: Thomson. 